\title{
Novel and emerging technologies for endovascular thrombectomy
}

\author{
Alexander G. Chartrain, BS, Ahmed J. Awad, MD, Justin R. Mascitelli, MD, Hazem Shoirah, MD, \\ Thomas J. Oxley, PhD, Rui Feng, MSc, Matthew Gallitto, BA, Reade De Leacy, MD, \\ Johanna T. Fifi, MD, and Christopher P. Kellner, MD
}

Department of Neurosurgery, Icahn School of Medicine at Mount Sinai, New York, New York

\begin{abstract}
Endovascular thrombectomy device improvements in recent years have served a pivotal role in improving the success and safety of the thrombectomy procedure. As the intervention gains widespread use, developers have focused on maximizing the reperfusion rates and reducing procedural complications associated with these devices. This has led to a boom in device development. This review will cover novel and emerging technologies developed for endovascular thrombectomy.

https://thejns.org/doi/abs/10.3171/2017.1.FOCUS16518
\end{abstract}

KEY WORDS acute ischemic stroke; large vessel occlusion; endovascular thrombectomy; stent retriever; aspiration catheter

$\mathrm{E}$ NDOVASCULAR thrombectomy is now the standard of care for eligible patients with acute ischemic stroke secondary to large vessel occlusion (LVO). ${ }^{40}$ Endovascular thrombectomy owes much of its success to the development of newer-generation devices, including stent retrievers and specialized aspiration catheters. ${ }^{4,28,34}$ It has equally benefitted from the establishment of hospital stroke networks and transfer protocols that have reduced the time from symptom onset to reperfusion. $2,3,29,33,45$ Improved diagnostic imaging techniques have also helped to more accurately identify eligible patients who might benefit from the procedure. ${ }^{4,7,28,34}$ Together, these efforts delivered improved functional outcomes in 5 seminal randomized trials. ${ }^{5,7,9,19,24,43,48,54}$ Despite these groundbreaking advances in endovascular stroke therapy, successful revascularization, as defined by Thrombolysis in Cerebral Infarction (TICI) Grade $2 b / 3$, is not always feasible and procedural complications are not uncommon., ${ }^{1,6,15,38,53}$ In addition to endovascular thrombectomy technique modifications, several device improvements and novel technologies have recently been introduced to improve revascularization success while reducing complication rates. Note that because these devices are new, supporting evidence for some of the claims that these devices advertise is the focus of ongoing research and is not yet available in the literature.

\section{Stent Retriever Devices}

Stent retriever thrombectomy devices work primarily by self-expanding into the surrounding vessel occlusion and integrating the thrombotic material into the stent's struts. Commonly used stent retrievers that are currently available include the Trevo ProVue (Stryker Neurovascular) and the Solitaire FR (Medtronic Neurovascular). They are deployed across an occluding thrombus by unsheathing an overlying microcatheter. As the stent retriever unfolds to engage the thrombus, it applies a radial force that compresses the thrombus against the vessel wall and immediately restores partial reperfusion of the distal vasculature. After allowing 2-5 minutes for the stent struts to adequately engage the thrombus, careful retraction of the stent and microcatheter as a single unit, under balloon guide catheter (BGC) occlusion or distal aspiration, removes the clot. The rate of TICI Grade 2b/3 achieved with the current stent retriever technology ranges from 59\% to $86 \%$, and 90-day modified Rankin Scale (mRS) scores of 0-2

ABBREVIATIONS ADAPT = A Direct Aspiration First Pass Technique; $B G C=$ balloon guide catheter; $E R I C=$ Embolus Retriever with Interlinked $\mathrm{Cages} ; \mathrm{ICH}=$ intracerebral hemorrhage; ID = inner diameter; LVO = large vessel occlusion; $\mathrm{mRS}=$ modified Rankin Scale; OD = outer diameter; $\mathrm{TICl}=$ Thrombolysis in Cerebral Infarction. SUBMITTED December 1, 2016. ACCEPTED January 20, 2017. INCLUDE WHEN CITING DOI: 10.3171/2017.1.FOCUS16518. 
range from $33 \%$ to $71 \% .^{7,9,19,24,43}$ The novel stent retrievers described below are designed to improve these rates and to reduce procedural complications.

\section{MicroVention Embolus Retriever With Interlinked Cages Stent Retriever}

The Embolus Retriever with Interlinked Cages (ERIC) stent retriever (MicroVention) was designed to reduce the amount of time needed for thrombus integration and, therefore, improve procedural time and efficiency. In contrast to traditional stent retriever thrombectomy, little or no time is required for thrombus integration with the ERIC device. The manufacturer suggests that the unique stent design with high intraluminal metal coverage allows for immediate retrieval into the guide catheter after deployment.

As the name suggests, the ERIC stent retriever is composed of spherical wire cages that are linked together in a linear array. The manufacturer offers several sizes, with diameters ranging from $3 \mathrm{~mm}$ to $6 \mathrm{~mm}$ and the number of linked spheres ranging from 3 to 5. Therefore, a range of working lengths is available (from $15 \mathrm{~mm}$ to $44 \mathrm{~mm}$ ). The number of deployed cages can also be adjusted based on the position of the microcatheter introducer sheath. The ERIC device was also designed with parallel struts to reduce the stent surface area in contact with the vessel wall, and therefore has the potential to reduce endothelial injury. Furthermore, the stent retriever's cross-section is designed so that stent processes span the intraluminal space, acting as a filter of sorts, with the potential to minimize distal embolization during the retrieval process.

A pilot study case series of 36 patients treated for acute ischemic stroke with the ERIC device achieved a reperfusion of TICI Grade $2 b / 3$ in $83.3 \%$ of cases and, at 90 days, $33.3 \%$ of patients had an mRS score of 0-2. ${ }^{27}$ Symptomatic intracerebral hemorrhage (ICH) occurred in 3 patients (8.3\%), which is similar to the rate reported in the Multicenter Randomized Clinical Trial of Endovascular Treat- ment for Acute Ischemic Stroke in the Netherlands (MR CLEAN). ${ }^{7}$ A separate case series of 34 patients reported a similar TICI Grade $2 b / 3$ revascularization rate of $79.4 \%$ and a 90 -day mRS score of $0-2$ in $48.4 \%$ of patients. ${ }^{41}$ None of these patients experienced symptomatic ICH within 24 hours of the procedure. These case series were both conducted in Europe, where the ERIC stent retriever is available for clinical use. Clinical trials with the device have yet to begin in the US and, therefore, it has not yet obtained US FDA approval (Table 1).

\section{Neuravi EmboTrap Stent Retriever}

The EmboTrap Revascularization Device (Neuravi Ltd.) simultaneously creates a reperfusion channel through the center of the thrombus and ensnares the occluding material into its struts. The unique design of the EmboTrap device includes an inner stent with a high radial force and an outer petal-shaped meshwork with a lower radial force (Fig. 1A). When deployed, the device's inner stent is designed to create a robust patent channel through the occlusion, which restores blood flow to the ischemic penumbra immediately and reduces the pressure gradient present on either side of the occlusion, an effect that has the potential to facilitate thrombectomy efforts. Although traditional stent retrievers are able to create a central channel through the thrombus, the procedure is only successful part of the time. The EmboTrap's outer meshwork is designed to have large inlets to maximize the amount of thrombus entrapped within the stent.

The EmboTrap II device, the successor to the original model, has an outer diameter (OD) of $5 \mathrm{~mm}$ and is available with a working length of $21 \mathrm{~mm}$ or $33 \mathrm{~mm}$. It has an articulated body designed to flex and maintain apposition with the vessel walls as the device is retracted around challenging vasculature and into larger-diameter vessels.

The EmboTrap devices have obtained European approval, but have yet to be cleared by the FDA. The Analysis of Revascularization in Ischemic Stroke with EmboTrap

TABLE 1. Device approvals and indications for cerebrovascular procedures

\begin{tabular}{llll}
\hline \multicolumn{1}{c}{ Device } & FDA Approved & FDA-Approved Indication & Supporting Evidence for FDA Approval \\
\hline MicroVention ERIC & No & NA* & NA \\
\hline Neuravi EmboTrap II & No & NA* & Prospective, single-arm, multicenter-ongoing \\
\hline Stryker Baby Trevo & Yes & Thrombectomy & Substantially equivalent \\
\hline Medtronic Mindframe Capture & Yes & Thrombectomy & Substantially equivalent \\
\hline Penumbra ACE68, Aspiration System & Yes & Thrombectomy & Prospective, single-arm, multicenter-completed \\
\hline Walk Vascular ClearLumen & No & NA† & Substantially equivalent \\
\hline Stryker AXS Catalyst 6 & Yes & Intracranial access & Substantially equivalent \\
\hline MicroVention Sofia Plus & Yes & Intracranial access & Substantially equivalent \\
\hline Medtronic Arc & Yes & Intracranial access & Substantially equivalent \\
\hline MIVI Neuroscience Mi-Axus & Yes & Intracranial access & Substantially equivalent \\
\hline DePuy Synthes Envoy DA & Yes & Intracranial access & Substantially equivalent \\
\hline BGCs & Yes & Intracranial access & Substantially equivalent \\
\hline Medtronic Lazarus Effect Cover & No & NA & NA \\
\hline
\end{tabular}

NA = not applicable.

* Approved for cerebrovascular thrombectomy in Europe.

$\dagger$ FDA approved for thrombectomy in the coronary vasculature. 


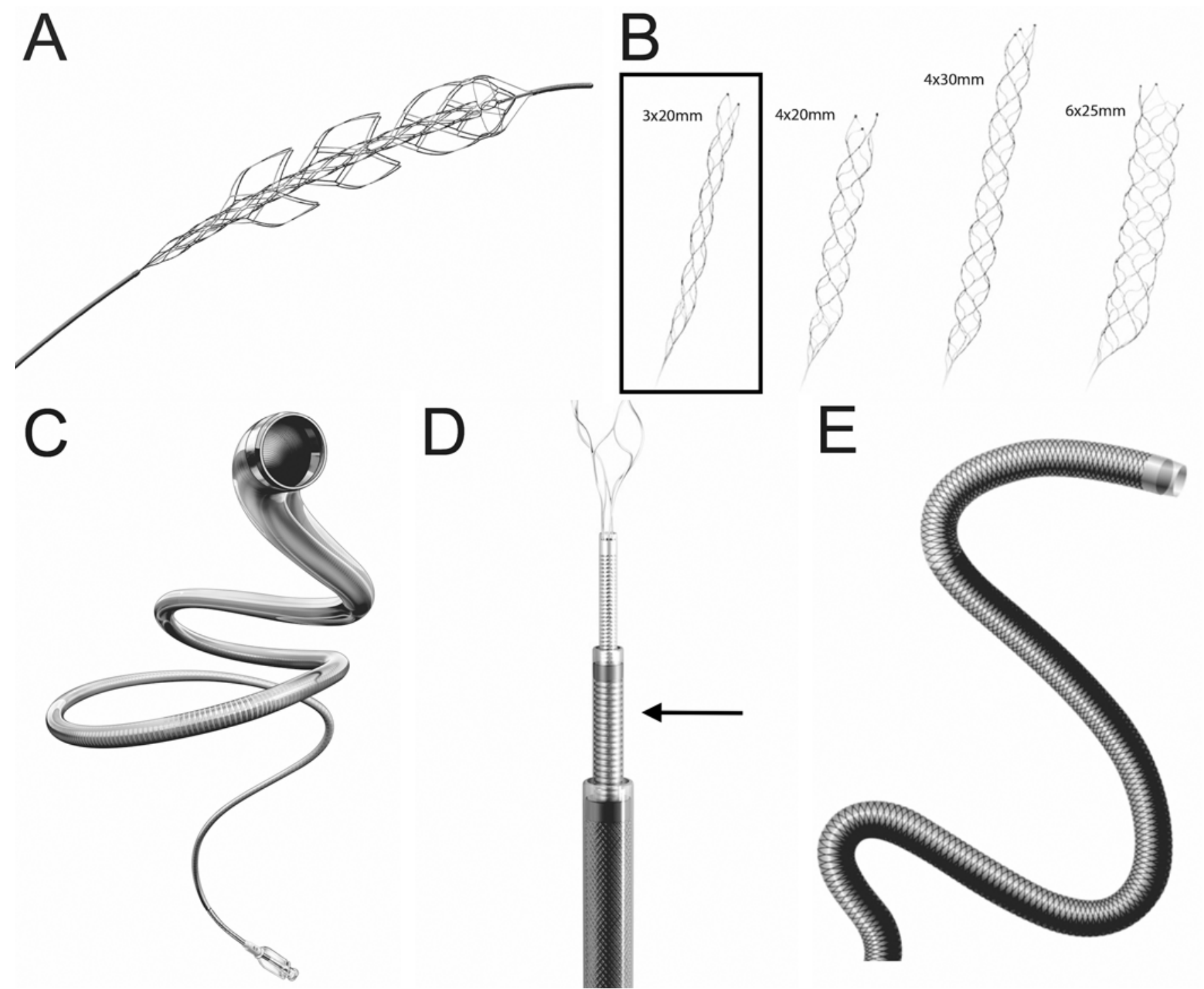

FIG. 1. Depictions of the devices reviewed in this study. A: Neuravi EmboTrap II Revascularization Device. Note that it is an investigational device that is not yet approved by the FDA. Copyright Neuravi Ltd. Published with permission. B: Stryker Trevo Provue $3 \times 20-\mathrm{mm}$ (inset), $4 \times 20-\mathrm{mm}, 4 \times 30-\mathrm{mm}$, and $6 \times 25-\mathrm{mm}$ devices. Images used courtesy of Stryker. C: Penumbra ACE68 aspiration catheter. Image used with permission from Penumbra, Inc. D: Stryker AXS Catalyst 6 intermediate catheter (arrow). Image used courtesy of Stryker. E: Sofia Plus intermediate catheter. Image used with permission from MicroVention, Inc.

(ARISE) clinical trial, based in Europe, is an ongoing prospective observational study that is investigating the performance characteristics and clinical outcomes associated with the device. The ARISE-II trial, a safety and efficacy trial based in the US and Europe, is concurrently ongoing to seek FDA device approval.

These trials were inspired by a pilot study case series of 40 patients. ${ }^{26}$ Following deployment, the EmboTrap system was able to create a patent channel within the occlusion, during the allotted thrombus integration time, in $73 \%$ of cases. A TICI $2 b / 3$ grade of reperfusion was achieved in $95 \%$ of cases, although $28 \%$ of these required the subsequent use of another device. Long-term follow-up was available for 23 patients and revealed that $35 \%$ had an mRS score of $0-2$ at 90 days. There was 1 symptomatic intracranial hemorrhage complication in this case series $(2.5 \%)$, and 2 other patients $(5 \%)$ experienced procedure-related dissection of the internal carotid artery, echoing rates that were reported in previously published studies. ${ }^{1,6,7,9,15,24,38,43,53}$ A subsequent abstract publication that included 42 patients, with overlap from the abovementioned study, elaborated on the long-term follow-up and found that $62 \%$ had an mRS score of $0-2$ and $18 \%$ had died at 90 days. ${ }^{46}$

\section{Stryker Neurovascular Trevo XP ProVue 3 × 20-mm Stent Retriever}

The Trevo XP ProVue 3 × 20-mm stent retriever ("Baby Trevo," Stryker Neurovascular) was specifically designed to address the need for a smaller and gentler device to treat occlusions in more distal branches with a better safety pro- 
file. Endovascular thrombectomy of the distal intracranial vasculature risks injury to the vessel wall and is limited by the larger size and high radial force of the currently available stent retrievers. As the name implies, the Baby Trevo device is smaller than the previous models, which include $4 \times 20-\mathrm{mm}, 4 \times 30-\mathrm{mm}$, and $6 \times 25-\mathrm{mm}$ stent retrievers (Fig. 1B). The smaller diameter increases the expansion of the cells that compose the stent system and may allow for improved embolus integration. ${ }^{21}$ The Baby Trevo is reported by the manufacturer to have a softer tip and a lower radial force across all vessel diameters than its larger counterparts, which may translate to a reduced likelihood of vessel injury, especially in vessels of smaller caliber. Its slender 3-mm diameter allows it to be delivered through a smaller, 0.017-in microcatheter and reach second- and third-degree arteries.

A small case series of 8 patients demonstrated that the Baby Trevo can retrieve distal vessel occlusions and downstream emboli, with reperfusion scores of TICI Grade $2 \mathrm{~b} / 3$ in $75 \%$ of cases. ${ }^{21}$ Vasospasm was common (63.5\%), although all cases resolved completely with intraarterial vasodilator treatment. Parenchymal hematomas occurred in 2 patients (25\%), who remained asymptomatic. No other complications were noted, including vessel perforation, arterial dissection, or subarachnoid hemorrhage. Two of $7(28.6 \%)$ patients had an mRS score of $0-2$ at 90 -day follow-up.

A subsequent, larger case series of 35 patients reported a TICI Grade $2 b / 3$ reperfusion score in $85.7 \%$ of patients. ${ }^{31}$ No instances of significant vasospasm requiring intraarterial treatment occurred. Asymptomatic parenchymal hematomas formed in 2 of 35 patients (5.7\%), a rate more consistent with previously published data. ${ }^{20,31}$ A 90-day $\mathrm{mRS}$ score of $0-2$ was achieved in $56.5 \%$ of patients. The Baby Trevo stent retriever is available in the US and is FDA approved for thrombectomy.

\section{Medtronic Mindframe Capture LP Stent Retriever}

The Mindframe Capture LP (Medtronic) is another stent retriever specifically designed to treat occlusions in arteries of small caliber. With an OD of $3 \mathrm{~mm}$, the Mindframe Capture stent retriever is as small as the Baby Trevo, discussed above. It can be delivered through a 0.017-in microcatheter and, therefore, has the potential to reach distal branches and may also be useful when treating LVOs in pediatric patients. ${ }^{44}$ A slightly larger model with an OD of $4 \mathrm{~mm}$ is available. The Mindframe Capture was approved for thrombectomy by European regulators in 2012, but only recently gained approval from the FDA (in 2015).

In an industry-sponsored Phase II clinical trial called Percutaneous Recanalization in Ischemic Stroke Management (PRIISM; NCT00810095), 40 patients with LVO underwent revascularization with the Mindframe Capture device (https://clinicaltrials.gov/ct2/show/NCT00810095). Revascularization to TICI Grade $2 / 3$ was achieved in $82.5 \%$ of cases, although a TICI Grade 2 breakdown was not specified. Intracranial hemorrhage occurred in 6 patients (15\%), although it was not specified what proportion of these were symptomatic. At 90-day follow-up, $47.5 \%$ of patients had an mRS score of $0-2$ and $20 \%$ had died.

In a subsequent case series of 10 patients treated for oc- clusion of the distal cerebral vasculature, thrombectomy with the Mindframe Capture was able to achieve TICI Grade $2 \mathrm{~b} / 3$ in $90 \%$ of patients. ${ }^{14}$ All 10 patients had presented with an occlusion in either a secondary or tertiary branch, and 3 of these were due to distal embolization resulting from prior proximal thrombectomy attempts or fibrinolysis. Long-term follow-up was not performed in this study, although $80 \%$ of patients demonstrated an improvement in National Institutes of Health Stroke Scale score following the procedure. Three patients $(30 \%)$ experienced a periprocedural ICH, 1 of which was symptomatic and eventually proved fatal.

In a third, recent case series of 9 patients who underwent revascularization with the Mindframe Capture device, $89 \%$ achieved TICI Grade $2 \mathrm{~b} / 3 .^{10}$ Of these patients, 6 had M2 occlusions and 5 occlusions were located in vessels smaller than $2 \mathrm{~mm}$ in diameter. No long-term follow-up was performed, although the median National Institutes of Health Stroke Scale score at discharge was 1. There were no intraprocedural or periprocedural complications, including no instances of ICH.

\section{Aspiration Devices}

Aspiration catheters offer an alternative strategy for achieving thrombus removal. They achieve vascular reperfusion by applying suction at the proximal portion of the occlusion and drawing it into the catheter lumen. Aspiration thrombectomy has developed an important role in acute ischemic stroke intervention and, as a part of A Direct Aspiration First Pass Technique (ADAPT), is an effective first-line therapy. ${ }^{50,51}$ The ADAPT method, which focuses on engaging the thrombus and removing it entirely intact, differs from previous techniques that used a separator wire to disrupt the thrombus at the tip of the catheter lumen. ${ }^{50}$ Furthermore, distal aspiration through intermediate catheters, in conjunction with stent retrievers, has been shown to reduce procedure times and decrease the number of passes needed for reperfusion. ${ }^{23}$ Balloon guide catheters can be used to halt anterograde blood flow in the affected vascular territory and serve to reduce distal embolization during thrombectomy attempts, although their utility is currently debated..$^{12,35,37,47,52}$ In addition, BGCs have been reported as a primary means for aspiration thrombectomy in proximal occlusions. ${ }^{17}$ Currently, the Penumbra aspiration catheters (Penumbra, Inc.) are the only catheters approved by the FDA for aspiration thrombectomy, and their use has resulted in TICI Grade $2 b / 3$ in $57 \%-84 \%$ of cases. ${ }^{16,30,42,49-51}$

\section{ACE68 Penumbra Aspiration Catheter}

Several Penumbra aspiration catheters have been developed for aspiration thrombectomy, including the 5MAX ACE (inner diameter [ID] 0.060 in) and the ACE64 (ID 0.064 in). Each of these catheters is compatible with the Penumbra continuous aspiration pump. With the release of each new catheter system, the ease and speed with which aspiration can be performed improves, as does the trackability of the newer catheters. Recently, the ACE68 (ID 0.068 in) aspiration catheter was introduced, which offers a larger orifice, greater aspiration strength, and is suggest- 
ed to have improved trackability in challenging anatomy (Fig. 1C). Reports of its use have yet to surface in the medical literature. The large-bore ACE68 has the potential to accelerate procedure times and improve both radiological and functional outcomes for patients. The ACE68 is available in the US and is approved by the FDA for aspiration thrombectomy.

\section{Walk Vascular ClearLumen Aspiration Catheter}

The ClearLumen aspiration catheter (Walk Vascular) adapts technology that exists for the treatment of coronary artery occlusions to ischemic stroke thrombectomy. The ClearLumen device combines thrombus aspiration and fragmentation by means of a high-pressure saline jet inside the catheter tip. ${ }^{8}$ The design aims to provide continuous aspiration while maintaining patency of the device. An initial case series of 20 patients undergoing thrombectomy for myocardial infarction demonstrated successful thrombus aspiration in $95 \%$ of patients. Distal embolization occurred in 1 case (5\%). Further trials and applications to the intracranial vasculature are warranted to investigate this device's potential. The ClearLumen aspiration catheter has FDA approval for use in the coronary and peripheral vasculature, but has yet to be adapted and approved for cerebrovascular applications.

\section{Intermediate Aspiration Catheters}

Intermediate catheters, typically used to deliver stent retrievers to distal branches, can also be used as aspiration catheters for thrombus removal. Several of these catheters have recently come to market, including the AXS Catalyst 6 ("Cat 6," Stryker Neurovascular), Sofia Plus (MicroVention), Arc (Medtronic Neurovascular), Mi-Axus (MIVI Neuroscience), and Envoy DA (DePuy Synthes). Although each of these devices has FDA approval for use in the intracranial vasculature, aspiration thrombectomy with these intermediate catheters is an off-label use.

The Cat 6 was designed to balance diameter, stiffness, and support to result in trackability and adequate distal access (Fig. 1D, arrow). It has an ID of 0.060 in at its tip and a $14-\mathrm{cm}$ flexible distal zone, which the manufacturer suggests provides good trackability in tortuous anatomy while maintaining high aspiration strength. No reports of its use for thrombectomy, either alone or in combination with stent retrievers, are available to date.

The Sofia Plus has a large ID of 0.070 in for aspiration thrombectomy or stent retriever delivery (Fig. 1E). In a small case series of 9 patients, the Sofia Plus catheter was used for aspiration thrombectomy both with and without concurrent use of a stent retriever. ${ }^{11}$ A reperfusion score of TICI Grade 2b/3 was achieved in all but 1 patient, and no procedural complications were encountered. Previous models of the Sofia catheter, with a smaller ID, have also been used successfully in aspiration and combined stent retriever thrombectomy. ${ }^{25}$

The Arc intracranial support catheter has the potential to be used alone for aspiration thrombectomy or in combination with a stent retriever to provide distal aspiration during retrieval. ${ }^{32}$ It has a distal ID of 0.061 in, with a high distal ID/OD ratio to allow for better trackability in tortu- ous anatomy and greater tip flexibility. A small case series of 3 patients in whom the Arc catheter was used for distal aspiration during stent retriever thrombectomy reported TICI Grade $2 b / 3$ in all 3 cases. ${ }^{32}$

The Mi-Axus is yet another novel intermediate catheter. It has a tapered design; its proximal portion has a 6-Fr lumen and the distal portion has a 5-Fr opening, which the manufacturer suggests increases distal trackability. Although there are no reports of its use in the literature to date, this catheter shows promise for both direct aspiration and combined stent retriever thrombectomy.

The Envoy DA guiding catheter, with an ID of 0.071 in, has the largest lumen currently available in its class, which therefore provides the greatest available aspiration force for thrombectomy. ${ }^{22}$ Although it is marketed as a guiding catheter, it has the potential to be used for manual aspiration of thrombus, especially occlusions in vessels of larger caliber (e.g., terminal internal carotid artery). No reports of its use in thrombectomy have been published in the literature to date.

\section{Accessory Devices \\ Lazarus Effect Cover for Distal Embolization Protection}

The Lazarus Effect Cover (Medtronic Neurovascular), a device with a funnel-shaped nitinol mesh at its distal end, was designed to surround the stent retriever and the entangled thrombus in a protective sheath during its retraction to prevent fragmentation and distal embolization. Following deployment of the stent retriever, the Lazarus Effect Cover is positioned at the proximal end of the stent retriever ${ }^{36}$ Retraction of the stent retriever against the device causes it to invert, roll over the outside of the stent retriever, and protect the thrombus against fragmentation and distal embolization. The Lazarus Effect Cover is compatible with any thrombectomy device that is delivered through a catheter smaller than 0.027 in, giving it wide applicability to both current and future devices.

In vitro experimentation has shown that the Lazarus Effect Cover reduces the rate of distal embolization in comparison with conventional guide catheter and BGC techniques. ${ }^{18,36}$ Although it has yet to be described, the combination of distal aspiration and the antiembolic device may have a synergistic benefit in the prevention of distal emboli. ${ }^{13}$ The feasibility and effectiveness was recently investigated in vivo with a small case series of 20 patients, in whom TICI Grade 2b/3 was achieved in $95 \%$ of cases. ${ }^{39}$ There were no instances of vascular injury or distal embolization to new vascular territories. The Lazarus Effect Cover shows promise for improving revascularization rates both alone and in combination with current aspiration technology. The Lazarus Effect Cover is available in Europe for clinical use, but has not begun clinical trials in the US or obtained FDA approval.

\section{Conclusions}

The novel stent retrievers, aspiration catheters, and distal embolus protection devices discussed here represent the next generation of technology designed to improve the success of endovascular thrombectomy. These tech- 
nologies have the potential to reach thrombi in more distal locations, reduce procedure times, improve revascularization rates, and translate to better functional outcomes for patients.

\section{References}

1. Akins PT, Amar AP, Pakbaz RS, Fields JD: Complications of endovascular treatment for acute stroke in the SWIFT trial with solitaire and Merci devices. AJNR Am J Neuroradiol 35:524-528, 2014

2. Alberts MJ, Latchaw RE, Jagoda A, Wechsler LR, Crocco $\mathrm{T}$, George MG, et al: Revised and updated recommendations for the establishment of primary stroke centers: a summary statement from the brain attack coalition. Stroke 42:26512665,2011

3. Alberts MJ, Latchaw RE, Selman WR, Shephard T, Hadley MN, Brass LM, et al: Recommendations for comprehensive stroke centers: a consensus statement from the Brain Attack Coalition. Stroke 36:1597-1616, 2005

4. Albuquerque FC, Fiorella D, Hirsch JA, Prestigiacomo C, Tarr RW: The tribulations of stroke trials. J Neurointerv Surg 5:181-183, 2013

5. Badhiwala JH, Nassiri F, Alhazzani W, Selim MH, Farrokhyar F, Spears J, et al: Endovascular thrombectomy for acute ischemic stroke: a meta-analysis. JAMA 314:18321843,2015

6. Behme D, Gondecki L, Fiethen S, Kowoll A, Mpotsaris A, Weber W: Complications of mechanical thrombectomy for acute ischemic stroke-a retrospective single-center study of 176 consecutive cases. Neuroradiology 56:467-476, 2014

7. Berkhemer OA, Fransen PSS, Beumer D, van den Berg LA, Lingsma HF, Yoo AJ, et al: A randomized trial of intraarterial treatment for acute ischemic stroke. N Engl J Med 372:11-20, 2015

8. Biasco L, Götberg M, Harnek J, Lundin A, Kandzari DE, De Backer O, et al: First-in-man experience with the ClearLumen thrombectomy system as an adjunctive therapy in primary percutaneous coronary interventions. J Interv Cardiol 29:155-161, 2016

9. Campbell BCV, Mitchell PJ, Kleinig TJ, Dewey HM, Churilov L, Yassi N, et al: Endovascular therapy for ischemic stroke with perfusion-imaging selection. N Engl J Med 372:1009-1018, 2015

10. Cerejo R, John S, Bauer A, Hussain MS, Bain M, Rasmussen P, et al: Emergent mechanical thrombectomy for acute stroke using the Mindframe Capture LP system: initial single-center experience. J Neurointerv Surg 8:1178-1180, 2016

11. Cerejo R, John S, Bauer A, Toth G, Bain M, Elgabaly M, et al: E-033 SOFIA plus distal access catheter for acute stroke intervention-initial single center experience. J Neurointerv Surg 8 (Suppl 1):A61, 2016 (Abstract)

12. Chueh JY, Kühn AL, Puri AS, Wilson SD, Wakhloo AK, Gounis MJ: Reduction in distal emboli with proximal flow control during mechanical thrombectomy: a quantitative in vitro study. Stroke 44:1396-1401, 2013

13. Chueh JY, Puri AS, Gounis MJ: An in vitro evaluation of distal emboli following Lazarus cover-assisted stent retriever thrombectomy. J Neurointerv Surg 9:183-187, 2017

14. Consigliere AB, Consigliere FJB, Lüttich A, Larrea JA, Zudaire EP, Juaristi IE, et al: C-2029 Restoring blood flow in distal branches of brain arteries with Mindframe Capture stentriever as endovascular treatment of acute ischemic stroke. Presented at the European Congress of Radiology 2013. (http://posterng.netkey.at/esr/viewing/index. php?module=viewing_poster\&doi=10.1594/ecr2013/C-2029) [Accessed February 14, 2017]

15. Dávalos A, Pereira VM, Chapot R, Bonafé A, Andersson T, Gralla J: Retrospective multicenter study of Solitaire FR for revascularization in the treatment of acute ischemic stroke. Stroke 43:2699-2705, 2012

16. Delgado Almandoz JE, Kayan Y, Young ML, Fease JL, Scholz JM, Milner AM, et al: Comparison of clinical outcomes in patients with acute ischemic strokes treated with mechanical thrombectomy using either Solumbra or ADAPT techniques. J Neurointerv Surg 8:1123-1128, 2016

17. Eesa M, Almekhlafi MA, Mitha AP, Wong JH, Goyal M: Manual aspiration thrombectomy through balloon-tipped guide catheter for rapid clot burden reduction in endovascular therapy for ICA L/T occlusion. Neuroradiology 54:1261-1265, 2012

18. Fargen KM, Mocco J, Gobin YP: The Lazarus funnel: a blinded prospective randomized in vitro trial of a novel CE-marked thrombectomy assist device. J Neurointerv Surg 8:66-68, 2016

19. Goyal M, Demchuk AM, Menon BK, Eesa M, Rempel JL, Thornton J, et al: Randomized assessment of rapid endovascular treatment of ischemic stroke. N Engl J Med 372:10191030,2015

20. Goyal M, Menon BK, van Zwam WH, Dippel DWJ, Mitchell PJ, Demchuk AM, et al: Endovascular thrombectomy after large-vessel ischaemic stroke: a meta-analysis of individual patient data from five randomised trials. Lancet 387:17231731,2016

21. Haussen DC, Lima A, Nogueira RG: The Trevo XP $3 \times 20 \mathrm{~mm}$ retriever ('Baby Trevo') for the treatment of distal intracranial occlusions. J Neurointerv Surg 8:295-299, 2016

22. Hu YC, Stiefel MF: Force and aspiration analysis of the ADAPT technique in acute ischemic stroke treatment. J Neurointerv Surg 8:244-246, 2016

23. Jindal G, Serulle Y, Miller T, Le E, Wozniak M, Phipps M, et al: Stent retrieval thrombectomy in acute stoke is facilitated by the concurrent use of intracranial aspiration catheters. J Neurointerv Surg [epub ahead of print], 2016

24. Jovin TG, Chamorro A, Cobo E, de Miquel MA, Molina CA, Rovira A, et al: Thrombectomy within 8 hours after symptom onset in ischemic stroke. N Engl J Med 372:2296-2306, 2015

25. Kabbasch C, Möhlenbruch M, Stampfl S, Mpotsaris A, Behme D, Liebig T: First-line lesional aspiration in acute stroke thrombectomy using a novel intermediate catheter: initial experiences with the SOFIA. Interv Neuroradiol 22:333-339, 2016

26. Kabbasch C, Mpotsaris A, Liebig T, Söderman M, Holtmannspötter M, Cronqvist M, et al: First-in-man procedural experience with the novel EmboTrap ${ }^{\circledR}$ revascularization device for the treatment of ischemic stroke-a European multicenter series. Clin Neuroradiol 26:221-228, 2016

27. Kahles T, Garcia-Esperon C, Zeller S, Hlavica M, Añon J, Diepers M, et al: Mechanical thrombectomy using the new ERIC retrieval device is feasible, efficient, and safe in acute ischemic stroke: a Swiss Stroke Center experience. AJNR Am J Neuroradiol 37:114-119, 2016

28. Khalessi AA, Fargen KM, Lavine S, Mocco J: Commentary: Societal statement on recent acute stroke intervention trials: results and implications. Neurosurgery 73:E375-E379, 2013

29. Kodankandath TV, Wright P, Power PM, De Geronimo M, Libman RB, Kwiatkowski T, et al: Improving transfer times for acute ischemic stroke patients to a comprehensive stroke center. J Stroke Cerebrovasc Dis 26:192-195, 2016

30. Kowoll A, Weber A, Mpotsaris A, Behme D, Weber W: Direct aspiration first pass technique for the treatment of acute ischemic stroke: initial experience at a European stroke center. J Neurointerv Surg 8:230-234, 2016

31. Kühn AL, Wakhloo AK, Lozano JD, Massari F, De Macedo Rodrigues K, Marosfoi MG, et al: Two-year single-center experience with the 'Baby Trevo' stent retriever for mechanical thrombectomy in acute ischemic stroke. J Neurointerv Surg [epub ahead of print], 2016 
32. Lozano JD, Massari F, Howk MC, de Macedo Rodrigues K, Brooks C, Perras M, et al: Utilization of a new intracranial support catheter as an intermediate aspiration catheter in the treatment of acute ischemic stroke: technical report on initial experience. Cureus 8:e617, 2016

33. Mascitelli JR, Wilson N, Shoirah H, De Leacy RA, Furtado SV, Paramasivam S, et al: The impact of evidence: evolving therapy for acute ischemic stroke in a large healthcare system. J Neurointerv Surg 8:1129-1135, 2016

34. Mocco J, Fiorella D, Fargen KM, Albuquerque F, Chen M, Gupta R, et al: Endovascular therapy for acute ischemic stroke is indicated and evidence based: a position statement. J Neurointerv Surg 7:79-81, 2015

35. Mokin M, Setlur Nagesh SV, Ionita CN, Levy EI, Siddiqui AH: Comparison of modern stroke thrombectomy approaches using an in vitro cerebrovascular occlusion model. AJNR Am J Neuroradiol 36:547-551, 2015

36. Mokin M, Setlur Nagesh SV, Ionita CN, Mocco J, Siddiqui AH: Stent retriever thrombectomy with the Cover accessory device versus proximal protection with a balloon guide catheter: in vitro stroke model comparison. J Neurointerv Surg 8:413-417, 2016

37. Nguyen TN, Malisch T, Castonguay AC, Gupta R, Sun CHJ, Martin CO, et al: Balloon guide catheter improves revascularization and clinical outcomes with the Solitaire device: analysis of the North American Solitaire Acute Stroke Registry. Stroke 45:141-145, 2014

38. Pereira VM, Gralla J, Davalos A, Bonafé A, Castaño C, Chapot R, et al: Prospective, multicenter, single-arm study of mechanical thrombectomy using Solitaire Flow Restoration in acute ischemic stroke. Stroke 44:2802-2807, 2013 (Erratum in Stroke 44:e239, 2013)

39. Piotin M, Redjem H, Ciccio G, Smajda S, Blanc R: A new device to prevent embolization in new territories during mechanical thrombectomy. Stroke 47 (Suppl 1):AWMP2, 2016 (Abstract)

40. Powers WJ, Derdeyn CP, Biller J, Coffey CS, Hoh BL, Jauch EC, et al: 2015 American Heart Association/American Stroke Association Focused Update of the 2013 Guidelines for the Early Management of Patients With Acute Ischemic Stroke Regarding Endovascular Treatment: a guideline for healthcare professionals from the American Heart Association/ American Stroke Association. Stroke 46:3020-3035, 2015

41. Raoult H, Redjem H, Bourcier R, Gaultier-Lintia A, DaumasDuport B, Ferré JC, et al: Mechanical thrombectomy with the ERIC retrieval device: initial experience. J Neurointerv Surg 0:1-4, 2016

42. Romano DG, Cioni S, Leonini S, Gennari P, Vallone IM, Zandonella A, et al: Manual thromboaspiration technique as a first approach for endovascular stroke treatment: a singlecenter experience. Interv Neuroradiol 22:529-534, 2016

43. Saver JL, Goyal M, Bonafe A, Diener HC, Levy EI, Pereira VM, et al: Stent-retriever thrombectomy after intravenous t-PA vs. t-PA alone in stroke. N Engl J Med 372:2285-2295, 2015

44. See AP, Kochis MA, Khandelwal P, Orbach DB: Considerations in applying a new stent retriever in pediatric endovascular cerebral thrombectomy for acute ischemic stroke. Pediatr Neurosurg 51:263-268, 2016

45. Smith EE, Schwamm LH: Endovascular clot retrieval therapy: implications for the organization of stroke systems of care in North America. Stroke 46:1462-1467, 2015
46. Söderman M, Brouwer PA, Andersson T, Thornton J: Neurointervention Embotrap revascularization device: initial experience in 49 patients from two European centers. Int J Stroke 10 (Suppl 2):157, 2015 (Abstract)

47. Stampfl S, Kabbasch C, Müller M, Mpotsaris A, Brockmann M, Liebig T, et al: Initial experience with a new distal intermediate and aspiration catheter in the treatment of acute ischemic stroke: clinical safety and efficacy. J Neurointerv Surg 8:714-718, 2016

48. Touma L, Filion KB, Sterling LH, Atallah R, Windle SB, Eisenberg MJ: Stent retrievers for the treatment of acute ischemic stroke: a systematic review and meta-analysis of randomized clinical trials. JAMA Neurol 73:275-281, 2016

49. Turk AS, Frei D, Fiorella D, Mocco J, Baxter B, Siddiqui A, et al: ADAPT FAST study: a direct aspiration first pass technique for acute stroke thrombectomy. J Neurointerv Surg 6:260-264, 2014

50. Turk AS, Spiotta A, Frei D, Mocco J, Baxter B, Fiorella D, et al: Initial clinical experience with the ADAPT technique: a direct aspiration first pass technique for stroke thrombectomy. J Neurointerv Surg 6:231-237, 2014

51. Vargas J, Spiotta A, Fargen K, Turner R, Chaudry I, Turk A: Long term experience using the ADAPT technique for the treatment of acute ischemic stroke. J Neurointerv Surg [epub ahead of print], 2016

52. Velasco A, Buerke B, Stracke CP, Berkemeyer S, Mosimann PJ, Schwindt W, et al: Comparison of a balloon guide catheter and a non-balloon guide catheter for mechanical thrombectomy. Radiology 280:169-176, 2016

53. Weber R, Nordmeyer H, Hadisurya J, Heddier M, Stauder M, Stracke P, et al: Comparison of outcome and interventional complication rate in patients with acute stroke treated with mechanical thrombectomy with and without bridging thrombolysis. J Neurointerv Surg [epub ahead of print], 2016

54. Yarbrough CK, Ong CJ, Beyer AB, Lipsey K, Derdeyn CP: Endovascular thrombectomy for anterior circulation stroke: systematic review and meta-analysis. Stroke 46:3177-3183, 2015

\section{Disclosures}

Dr. Fifi has direct stock ownership in Cerebrotech, and she is a consultant for Penumbra, Inc., and MicroVention, Inc. She receives support for a non-study-related clinical or research effort that she oversees from Stryker and from MicroVention, Inc.

\section{Author Contributions}

Conception and design: Kellner, Chartrain, Awad. Drafting the article: Chartrain. Critically revising the article: all authors. Reviewed submitted version of manuscript: all authors. Study supervision: Kellner.

\section{Supplemental Information Videos}

Video Abstract. https://vimeo.com/207111732.

\section{Correspondence}

Christopher P. Kellner, The Mount Sinai Hospital, Klingenstein Clinical Center, 1-North, 1450 Madison Ave., New York, NY 10029. email: christopher.kellner@mountsinai.org. 